Article

\title{
Mapping Land Management Regimes in Western Ukraine Using Optical and SAR Data
}

\author{
Jan Stefanski ${ }^{1, *}$, Tobias Kuemmerle ${ }^{2}$, Oleh Chaskovskyy ${ }^{3}$, Patrick Griffiths ${ }^{2}$, \\ Vassiliy Havryluk ${ }^{3}$, Jan Knorn ${ }^{2}$, Nikolas Korol ${ }^{3}$, Anika Sieber ${ }^{2}$ and Björn Waske ${ }^{1}$ \\ ${ }^{1}$ Institute of Geographical Sciences, Freie Universität Berlin, Malteserstrasse 74-100, \\ 12249 Berlin, Germany; E-Mail: bjoern.waske@fu-berlin.de \\ ${ }^{2}$ Geography Department, Humboldt-Universität zu Berlin, Unter den Linden 6, \\ 10099 Berlin, Germany; E-Mails: tobias.kuemmerle@geo.hu-berlin.de (T.K.); \\ patrick.griffiths@geo.hu-berlin.de (P.G.); jan.knorn@geo.hu-berlin.de (J.K.); \\ anika.sieber@geo.hu-berlin.de (A.S.) \\ ${ }^{3}$ Institute of Forest Management, Ukrainian National Forestry University, vul. Gen. Chuprynky, \\ 103, 79031 Lviv, Ukraine; E-Mails: oleh.chaskov@googlemail.com (O.C.); \\ vasil-gavriluk@ rambler.ru (V.H.); nikkorol@ukr.net (N.K.) \\ * Author to whom correspondence should be addressed; E-Mail: j.stefanski@ fu-berlin.de; \\ Tel.: +49-30-838-62831; Fax: +49-30-838-70760.
}

Received: 28 March 2014; in revised form: 27 May 2014 / Accepted: 3 June 2014 /

Published: 6 June 2014

\begin{abstract}
The global demand for agricultural products is surging due to population growth, more meat-based diets, and the increasing role of bioenergy. Three strategies can increase agricultural production: (1) expanding agriculture into natural ecosystems; (2) intensifying existing farmland; or (3) recultivating abandoned farmland. Because agricultural expansion entails substantial environmental trade-offs, intensification and recultivation are currently gaining increasing attention. Assessing where these strategies may be pursued, however, requires improved spatial information on land use intensity, including where farmland is active and fallow. We developed a framework to integrate optical and radar data in order to advance the mapping of three farmland management regimes: (1) large-scale, mechanized agriculture; (2) small-scale, subsistence agriculture; and (3) fallow or abandoned farmland. We applied this framework to our study area in western Ukraine, a region characterized by marked spatial heterogeneity in management intensity due to the legacies from Soviet land management, the breakdown of the Soviet Union in 1991, and the recent integration of this region into world markets. We mapped land management regimes using a hierarchical,
\end{abstract}


object-based framework. Image segmentation for delineating objects was performed by using the Superpixel Contour algorithm. We then applied Random Forest classification to map land management regimes and validated our map using randomly sampled in-situ data, obtained during an extensive field campaign. Our results showed that farmland management regimes were mapped reliably, resulting in a final map with an overall accuracy of $83.4 \%$. Comparing our land management regimes map with a soil map revealed that most fallow land occurred on soils marginally suited for agriculture, but some areas within our study region contained considerable potential for recultivation. Overall, our study highlights the potential for an improved, more nuanced mapping of agricultural land use by combining imagery of different sensors.

Keywords: land use intensity; post-soviet land use change; multi-sensor; landsat; SAR; land systems; land management; Ukraine

\section{Introduction}

Human-caused land use and land cover change is one of the major drivers of global environmental change [1,2]. Historically, agricultural expansion was the principal mode of land use change leading to, for example, an increasement of cropland areas by about 550\% over the last three centuries [3]. Nowadays, up to $38 \%$ of the land surface is used for agriculture and every year about 13 million hectares covered by natural vegetation are transformed into agricultural land $[1,4]$. Next to agricultural expansion, agricultural intensification has recently become an important mode of reaching higher agricultural outputs [5-7]. Especially since the advent of industrial fertilizer and the green revolution, intensification has been responsible for the majority of yield increases in recent decades [6-9].

Both agricultural expansion and intensification entail substantial environmental trade-offs. Approximately $35 \%$ of the anthropogenic $\mathrm{CO}_{2}$ emissions since 1850 are directly traced back to land use changes [1]. On the one hand, expansion of agriculture into native ecosystems is the major driver of biodiversity loss, releases huge amounts of carbon and plays a major role in changing the global carbon cycle [10]. On the other hand, agricultural intensification can increase soil erosion, lower soil fertility, threaten biodiversity, pollute ground water and lead to the eutrophication of rivers and lakes, and contribute to climate change via the emission of $\mathrm{CO}_{2}$ and other green-house gases [8]. Mapping the extent and the intensity of agriculture is therefore important for assessing environmental and socio-economic trade-offs of agriculture.

As demand for agricultural products (e.g., food, feed, bioenergy) continues to increase and land resources are increasingly becoming scarce [11,12], identifying strategies for increasing agricultural production in sustainable ways has become a research priority $[13,14]$. There are three strategies that could lead to increasing agricultural production: (1) cultivation of new farmland; (2) intensifying existing farmland; or (3) recultivation of unused or abandoned farmland. However, assessing where sustainable intensification or recultivation could be fostered, requires improved maps that go beyond broad land 
cover classes such as cropland and are sensitive to land use intensity and that include information on active and fallow/abandoned agriculture. Unfortunately, such information does not exist for most parts of the globe $[15,16]$.

Satellite remote sensing has doubtless become the most important technology to monitor agricultural land use and changes therein [17-21]. Yet, existing approaches to do so have mainly focused on cropland extent and the proximate drivers, leading to changes in cropland area (e.g., deforestation due to agricultural expansion, agricultural abandonment) [22,23]. What is generally lacking are methods able to capture the heterogeneity and the varying management intensity within the broad agricultural class.

One reason for the lack of approaches sensitive to land use intensity is that intensity in itself is a complex and multidimensional term. Agricultural land use intensity can be measured via inputs to agriculture (e.g., fertilizer, pesticide application rate), the outputs from agriculture (e.g., yields), or in terms of system properties that change due to management (e.g., human appropriation of net primary production) $[15,24,25]$. Unfortunately, remote sensing can only rarely measure any of these dimensions directly and therefore a combination of remote sensing and ground-based data is often needed to determine land use intensity metrics. This is problematic because comprehensive and detailed in-situ data on land management is unavailable for most parts of the world, either because of the lack of monitoring schemes or the confidentiality issues [15,26,27]. Approaches that allow to better characterize management intensity directly from satellite imagery are therefore potentially highly beneficial for a better understanding of the impacts of agriculture on the environment.

A promising avenue for a more nuanced representation of agriculture is to identify and map management regimes with different intensities [15,27]. Such management regimes (or land systems) may be easier to map than all the individual dimensions of management intensity itself, yet provide a proxy variable for tracking changes in management intensity and their impacts (e.g., shifts from subsistence to capital intensive farming). A few studies have used such approaches recently at the global scale. For example, combining land cover data with human population density allowed deriving anthromes of varying land use intensity [28]. Or, using clustering techniques on a comprehensive set of environmental and socio-economic variables allowed to map land system archetypes [29].

Likewise, combining global data sets on cropland extent, yield gaps, livestock distribution, and market accessibility allowed to map different "land use systems", which represented different levels of management intensity [29,30]. Examples relying on remote sensing data to characterize land management regimes are even scarcer. At the regional scale, Landsat images were used to map swidden agricultural systems of varying management intensities for Laos [31]. Furthermore, the spatial distribution of farming types in Ethiopia was analyzed based on Landsat, but additionally to remote sensing data, local spatial contextual information was needed [32]. While these studies highlight the value of mapping management intensity regimes, there is a general lack of studies developing methods to map management regimes using remote sensing data.

One important indicator to characterize agricultural land use intensity is field size, which is a proxy variable for the degree of mechanization. While small fields indicate low levels of mechanization, often accompanied by low levels of fertilizer and pesticide use, large fields tend to require a high degree of mechanization and are typical for industrialized agriculture [33,34]. Mapping land management regimes that differ in field sizes (e.g., large-scale cropland and small-scale cropland) is challenging 
due to spectral similarities of fields and mixed signatures within groups of small fields. Studies mapping field sizes based on remote sensing data are scarce. While some remote sensing-based studies used predefined vector data or texture measures to analyze field sizes [35-39] or an object-based approach using Landsat data to extract fields [40], there is no classification-based approach to directly derive management regimes differing in field sizes up to now.

Object-based approaches use additional information compared to pixel-by-pixel approaches, for example, spatial context and object-based features such as spectral mean or variance. Object-based classification of land use and land cover often results in higher accuracies, when compared to pixel-based classifications [41-44]. Some studies also used hierarchical classification approaches, mainly to integrate different data types into a comprehensive mapping framework [45-48]. However, to our knowledge, no study has used segmentation algorithms to make better use of field size information inherent in satellite images in order to improve the mapping of agricultural management intensity.

Landsat has arguably become the most important sensor to characterize land cover and land use at regional to landscape scale [49-52], especially since the recent opening of the United States Geological Survey (USGS) Landsat archives [53]. However, Landsat data availability can be limited in regions of persistent cloud cover or due to the relatively low revisiting rates of the Landsat sensors (16 days). For example, the limits regarding image acquisition dates and temporal coverage are critical for the mapping accuracy of agricultural abandonment [54,55].

Contrary to optical data, synthetic aperture radar (SAR) data are almost independent from weather conditions. Thus, multitemporal data sets covering any stage from one growing season in regions like Central Europe can reliably be produced by using SAR sensors. Several studies used SAR data for land use and land cover mapping [56-58]. In addition, SAR data provides different, but complementary information on land cover, when compared to optical data. For example, discriminating vegetation species can be difficult due to their similar spectral signature. In this case, radar can contribute with signal differences in surface roughness, shape, and moisture content of the observed ground [59].

Jointly using optical and SAR data to map land use and land cover change is therefore an attractive option, but has so far rarely been employed. This is unfortunate because such multisensor approaches can result in more reliable maps than using only one data source alone. For example, the fusion of multispectral and SAR data from an agricultural area outperforms the mono-sensoral approach in terms of the classification accuracy [60]. Overall, several studies noted higher accuracies in the differentiation of classes by the combined use of optical and SAR data in context of land use and land cover mapping [61-64], for example by minimizing spectral ambiguities and improving the characterization of phenological variability [65]. However, none of these studies have assessed how the combined use of optical and SAR data can advance the mapping of management intensity of cropland.

Here, we explore the synergetic effect of multispectral Landsat and SAR data to map land management regimes, as proxies of land use intensity, in our study area in western Ukraine. Land use intensity here refers to the management intensity in terms of capital-related inputs such as industrial fertilizer, pesticides, or heavy machinery. Eastern Europe and especially western Ukraine are particular interesting for mapping land management regimes [22,66,67]. Land management in the region has changed drastically in recent decades, triggered by the breakdown of the Soviet Union in 1991, when industrialized and the large agricultural fields, established during Soviet times, were abandoned [68,69]. 
Furthermore, large fields were converted to small fields as subsistence agriculture became important after 1991 [66,68,70,71]. Recently, global trends in food prices have led to a growing interest in the region, which triggered the recultivation of much farmland and a renaissance of industrial agriculture, including a consolidation of small fields into large ones [72]. The rates and patterns of these trends remain unclear, however, especially with regard to changes in management intensity, which in this region is intimately linked to changes in agricultural field size. Mapping land management regimes can therefore offer important insights about land use change and ultimately the effect of economic and institutional drivers on land change in western Ukraine.

The overall goal of our study was to develop an approach for mapping agricultural land management regimes of different intensities for our study area in western Ukraine, and to use this methodology to assess the patterns and rates of agricultural land use in this region. To do so, we used field size (large-scale cropland and small-scale cropland) as a proxy for management intensity and evaluated the potential of object-based image analysis to merge multispectral and SAR images within a hierarchical classification framework in order to discriminate different land cover/use categories, including different land management regimes. Specifically, our objectives were to:

1. Analyze whether object-based mapping improves the separation of land management regimes

2. Assess whether the combination of multispectral and SAR data enhances the classification of land management regimes.

3. Map land management regimes and analyze them across gradients of soil marginality, elevation, and distance to markets.

\section{Material}

\subsection{Study Area}

Our study area is located in Volynska and Lvivska Oblasts in western Ukraine and covers about $7500 \mathrm{~km}^{2}$ (Figure 1). The study area contains seven raions (i.e., administrative unit at the district-level). In addition, the three cities Volodymyr-Volynsky, Novovolynsk, and Chervonograd are self-governing municipalities. Elevation in the study area varies from about $150 \mathrm{~m}$ to $300 \mathrm{~m}$. The climate is temperate continental with average temperatures from $-2.9{ }^{\circ} \mathrm{C}$ in January to $19.0^{\circ} \mathrm{C}$ in July [73]. The region is dominated by agricultural land use and forests. Soil types vary within the study area with mainly Podzols and Gleysols in the wooded northern and southern part and Phaeozems as well as Chernozems in the central part. Approximately half of the population in the region is living in rural areas [74].

The study area in western Ukraine is particular interesting to investigate land management regimes because it comprises a large variability of socio-economic and environmental conditions, resulting in a large heterogeneity of management practices. The Soviet land management was characterized by collectivized and large-scale farmland [71]. With the collapse of the Soviet Union in 1991, the region experienced drastic changes in institutions and socio-economic conditions. For example, the collapse of the Soviet Union and associated economic changes (e.g., price liberalization, rising competition, and breakaway of former markets) resulted in the substantial abandonment of agricultural fields on the one hand, and an emergence of a substantial subsistence agriculture sector on the other hand $[66,68,72]$. 
Furthermore, changes in the land ownership lead to farmland fragmentation [72]. More recently, recultivation of abandoned land and conversion of subsistence farming to large-scale farming has become common.

Figure 1. Map of the study area in western Ukraine. (A) Study area boundaries (grey); (B) Location of the study area in Europe; (C) Landsat footprint (green) and ERS footprint (red); (D) Administrative boundaries of (a) Turiyskyi Raion; (b) Volodymyr-Volynskyi Raion; (c) Lokachynskyi Raion; (d) Ivanychivskyi Raion; (e) Horokhivskyi Raion; (f) Sokalskyi Raion; and (g) Radekhivskyi Raion.

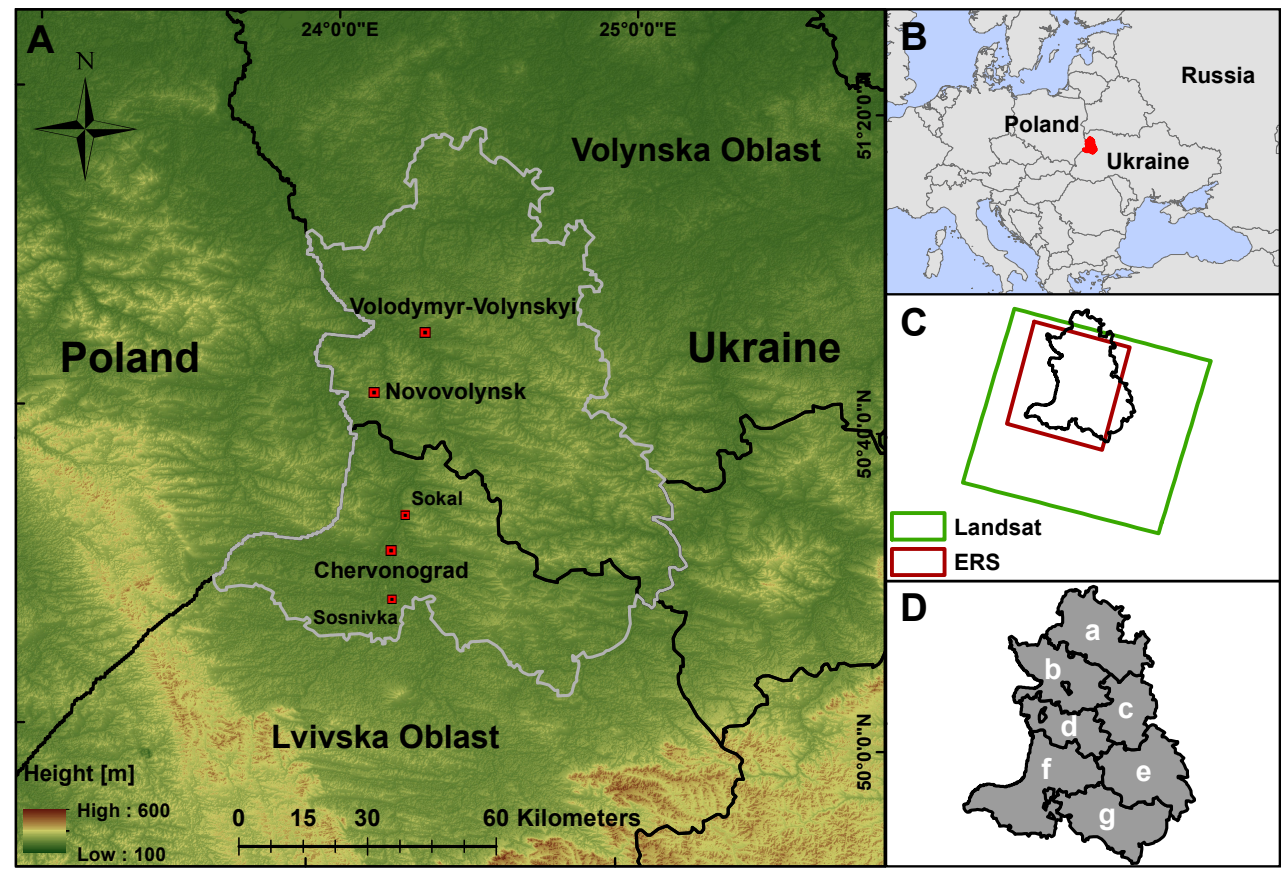

We decided to map the following land use and land cover classes (Table 1). The four agricultural management regimes we mapped comprised large-scale cropland (LSC), small-scale cropland (SSC), fallow and pasture (Figure 2). While LSC is a potential indicator for intensive agricultural use, fallow areas are abandoned or currently unused fields. SSC refers to subsistence agriculture and kitchen gardens, and thus indicates low management intensity. Forest and urban completed the land use/cover categories in the study area.

Table 1. Land categories, defined classes, class descriptions.

\begin{tabular}{lll}
\hline Categories & Classes & Description \\
\hline Agriculture & Large-scale cropland & $\begin{array}{l}\text { Potentially intensive use; large fields (100 ha) indicating a high degree of } \\
\text { mechanization and other capital-related inputs (e.g., pesticides, fertilizer) }\end{array}$ \\
\hline Agriculture & Small-scale cropland & $\begin{array}{l}\text { Kitchen gardens, subsistence agriculture; small field size indicates } \\
\text { high labor intensity, but low intensity in terms of capital related inputs }\end{array}$ \\
\hline Agriculture & Pasture & Grassland used for grazing of cattle, sheep, or goats \\
\hline Agriculture & Fallow & $\begin{array}{l}\text { Areas without sign of management, including perennial vegetation (often willow, } \\
\text { alder or birch shrubs), all indicating potentially abandoned agricultural land }\end{array}$ \\
\hline Forestry & Forest & Mixed forest or forests dominated by coniferous or deciduous forests species \\
\hline Urban & Urban & Dense settlements or cities \\
\hline
\end{tabular}


Figure 2. Photos of the agricultural category taken during our field campaign. (A) Large-scale cropland (B) Small-scale cropland (C) Pasture (D) Fallow/potential abandoned, high grass with some bushes.
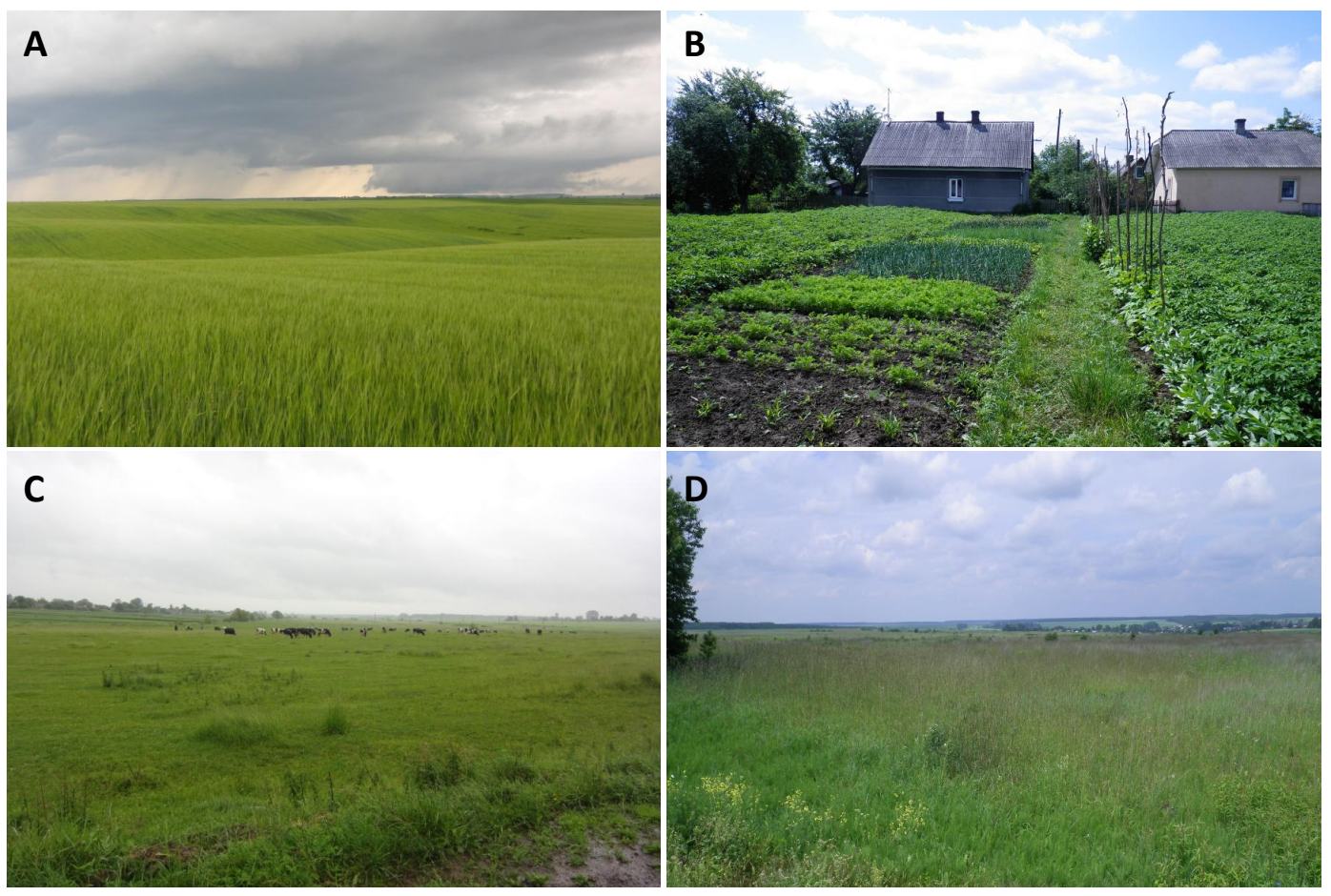

\subsection{Data Set and Preprocessing}

To map the different land use/cover classes including our land management intensity regimes, we acquired multispectral Landsat TM data (30 m resolution) and ERS-2 SAR data (about $25 \mathrm{~m}$ spatial resolution). We used a total of two Landsat scenes (7 June 2010 and 14 November 2010, path/row 185/25) and nine ERS-2 scenes (each month in 2010 except for January, May, and August). The Landsat images were already preprocessed to level L1T, which ensures a sufficient geometric and radiometric accuracy for our analysis [75]. The ERS-2 data were ordered in a single look complex (SLC) image format. Preprocessing of SAR data was carried out with NEST-4C. Standard SAR preprocessing was applied, containing radiometric and geometric corrections as well as multitemporal speckle-filtering. The ERS-2 images were resampled to a 30 meter pixel size to match the resolution of the Landsat TM data for all subsequent analysis.

We used additional data to analyze the land management regimes map. To receive information about soil qualities, an Ukrainian soil map with a scale of 1:1,000,000 was digitized in-house. Elevation data was derived from the digital elevation model of the Shuttle Radar Topography Mission (SRTM) (Figure 1A). Furthermore, a map with buffer zones around the cities was prepared with GIS analysis. We used a city layer created on the basis of a topographic map from OpenStreetMaps (OSM) and visual interpretation. Only cities with more than 10,000 inhabitants were taken into account (Figure 1A).

We acquired in-situ data during an extensive field campaign in 2012 and controlled the data for validity in the study period (2010) by visually inspecting high-resolution imagery. We used a random clustered sampling technique to allocate 357 points to be used for the validation data set. To do so, 
we generated 40 clusters, where each cluster contained five points in a (+) shape with a distance of $100 \mathrm{~m}$ between points along the horizontal and vertical axis. Three teams, each containing two to three surveyors, accessed each point in the field, noted the land use/cover at the point and photo documented the area in each direction from the point. The survey protocol was derived from the Land Use and Cover Area frame Survey (LUCAS) guidelines [76]. We created a field protocol with land use and land cover categories based on the LUCAS guidelines, which contained hierarchical land cover categories (e.g., agriculture $\rightarrow$ arable land $\rightarrow$ cereals/root crops $\rightarrow$ wheat/potatoes) and as well as land use categories (e.g., agriculture/fallow and abandoned land/kitchen gardens). In a last step, we expanded the set of five points assessed in the field to a nine point $(3 \times 3)$ grid, using the field photos and on-screen interpretation of high-resolution RapidEye data to determine the land use/cover category of the additional four points per cluster. Three sample points were removed, due to inaccessibility in the field and uncertainty in on-screen interpretation. Thus, the reference set contains 357 points.

The training data acquisition was also based on the field campaign and was additionally supported by visual interpretation of RapidEye data. The training data was generated independently from the test data set. To do so, we ensured that the (1) training and test data are spatially disjoint and (2) no training and test data are located within the same field plot.

\section{Methods}

To map land management regimes in our study region, we compare (1) a pixel-based (Landsat); (2) an object-based (Landsat); and (3) a hierarchical object-based classification approach (Landsat+ERS) in terms of the mapping accuracy. The following sections introduce the underlying methods for these three approaches.

\subsection{Random Forest Classifier}

We chose a Random Forest (RF) classifier for all three approaches. RF performs efficiently with large data sets, is robust to outliers and overfitting, and its parameter selection is user-friendly [77]. The RF has demonstrated excellent performance in terms of classifying diverse remote sensing data sets [44,56,78-80] and especially joint optical and radar data sets [63,81].

Random Forests are based on a combination of a set of $k$ different decision tree classifiers. Decision trees have a tree-like hierarchy, consisting of a root node, which includes all samples, internal or split nodes that contain a decision rule, and final leave nodes, representing the different classes. A majority vote is used to combine the outputs by the $k$ decisions trees to generate the final classification result. Each tree in the RF is trained by a randomly selected subset of the training data. The remaining training samples, which are called "out-of-bag" (OOB), enable a cross-validation-like accuracy measure through the OOB error estimate. The RF split rules are based on a subset $m$ of all $n$ features, whereby $m$ is a user-defined value, with $m<n$. As RF parameters, we used standard values such as 500 trees for $k$ and the square root of the total input features for $m$. However, the classification accuracy is relatively insensitive to the RF parameters [77,78].

In this study, the classification model was generated with 1000 training samples per class, which were selected by an equalized random sampling out of the training set. 


\subsection{Superpixel Contour Segmentation}

To perform an image segmentation, we used the Superpixel Contour (SPc) segmentation algorithm in combination with a semi-automatic parameter selection [44]. The SPc, introduced by Mester et al. (2011) [82], is an iterative, region-based segmentation algorithm. The principle of the SPc is to optimize a non-specified initial segmentation to separate the image into homogenous regions (i.e., segments or superpixels, ideally representing real-world objects). Therefore, the initial segmentation is optimized along its boundaries based on the statistical distribution of each region. The boundary pixels are assigned to the region that maximizes the posterior distribution. The general principle behind this is an iteratively running maximum-a-posteriori (MAP) segmentation. The SPc algorithm is computationally efficient as only the boundary pixels of each region are taken into account for the optimization process.

The SPc segmentation algorithm has four parameters. However, SPc is generally user-friendly as only two (parameter $G$ and $B$ ) out of four parameters have to be adapted to the respective application [44]. The user can control the scale of the segments with $G$ and the shape of the segments with $B$. Stefanski et al. (2013) [44] introduced a concept to semi-automatically select the optimal segmentation parameters with respect to the classification accuracy, which was used in this study. The basic idea of the concept is to define a set of parameters for $G$ and $B$ that are segmented by SPc and evaluated by the OOB error rate of the RF. Then, the best parameter combination based on the classification accuracy can be used for subsequent object-based classifications. This approach is comparable with a grid-search which is, for example, frequently used to select the parameters of Support Vector Machines [83].

The identification of an ideal segmentation level for all classes is often challenging. Moreover, different segmentation levels can provide different types of information [63,84]. Waske and van der Linden (2008) [63] proposed a multilevel segmentation strategy for the classification of SAR and multispectral data. They demonstrated that both aspects, the combination of information from different sensor sources as well as the use of multiple segmentation levels, proved useful in terms of accuracy. Thus, using the parameter optimization approach mentioned above, we analyzed various segmentation levels (i.e., segmentation scales based on different values for $G$ ) for the land management regimes in our study area. The class-specific OOB error rate, provided by the RF, enables the detection of the "optimal" representation for each class in terms of the segmentation level and the classification accuracy. For example, the classification accuracy of large-scale cropland increased with higher segmentation levels while the effect was vice versa with the accuracy of urban areas. Initial tests showed that the subclasses of active agriculture (i.e., LSC, SSC, and pasture) were difficult to classify solely on pixel-level due to spectral similarities. We used object-based analysis to overcome this issue, however, the class-specific analysis showed that there is no single object-size that results in a high classification accuracy. This can be explained by the inhomogeneous object-sizes within SSC and pasture.

Therefore, we used three segmentation levels $(G=15,20,25)$ in addition to the original pixel information. As object-based features, we derived the mean value for Landsat and the mean value and standard deviation for ERS-2 SAR. Thus, the dimension of the feature space is 111, containing the pixel information from the two Landsat images (i.e., 2 images $\times 6$ bands) and 9 SAR images (i.e., 9 images $\times 1$ band), the segments' mean derived from Landsat $(2 \times 6 \times 3$ segmentation levels $)$ 
and ERS-2 SAR (i.e., $9 \times 1 \times 3$ segmentation levels), and the standard deviation from ERS-2 SAR (i.e., $9 \times 1 \times 3$ segmentation levels).

\subsection{Hierarchical Classification Framework}

We used a hierarchical classification framework to integrate optical and SAR data as well as object-based features from different scales into one classification scheme (Figure 3). For each of the three classification levels (1-3), a separate classification model was generated. (1) First, active agriculture, fallow, forest and urban were classified. For this step, a single-level object-based approach based on Landsat and ERS-2 features was used; (2) Second, active agriculture was separated further in either cropland or pasture. To do so, a multilevel, object-based classification based on Landsat and ERS-2 data was used; (3) The last classification differentiated cropland into large-scale and small-scale cropland, using the same input features as in Step 2. After performing the classification, indicators for land management intensity were derived from the generated map Figure 3(4).

Figure 3. Diagram showing the hierarchical classification framework and derived indicators for management intensity. (1) Classification of active agriculture, fallow, forest and urban; (2) Classification of cropland and pasture within active agriculture; (3) Classification of large-scale and small-scale cropland; (4) Indicators of land management, derived from the hierarchical classification.

(1)

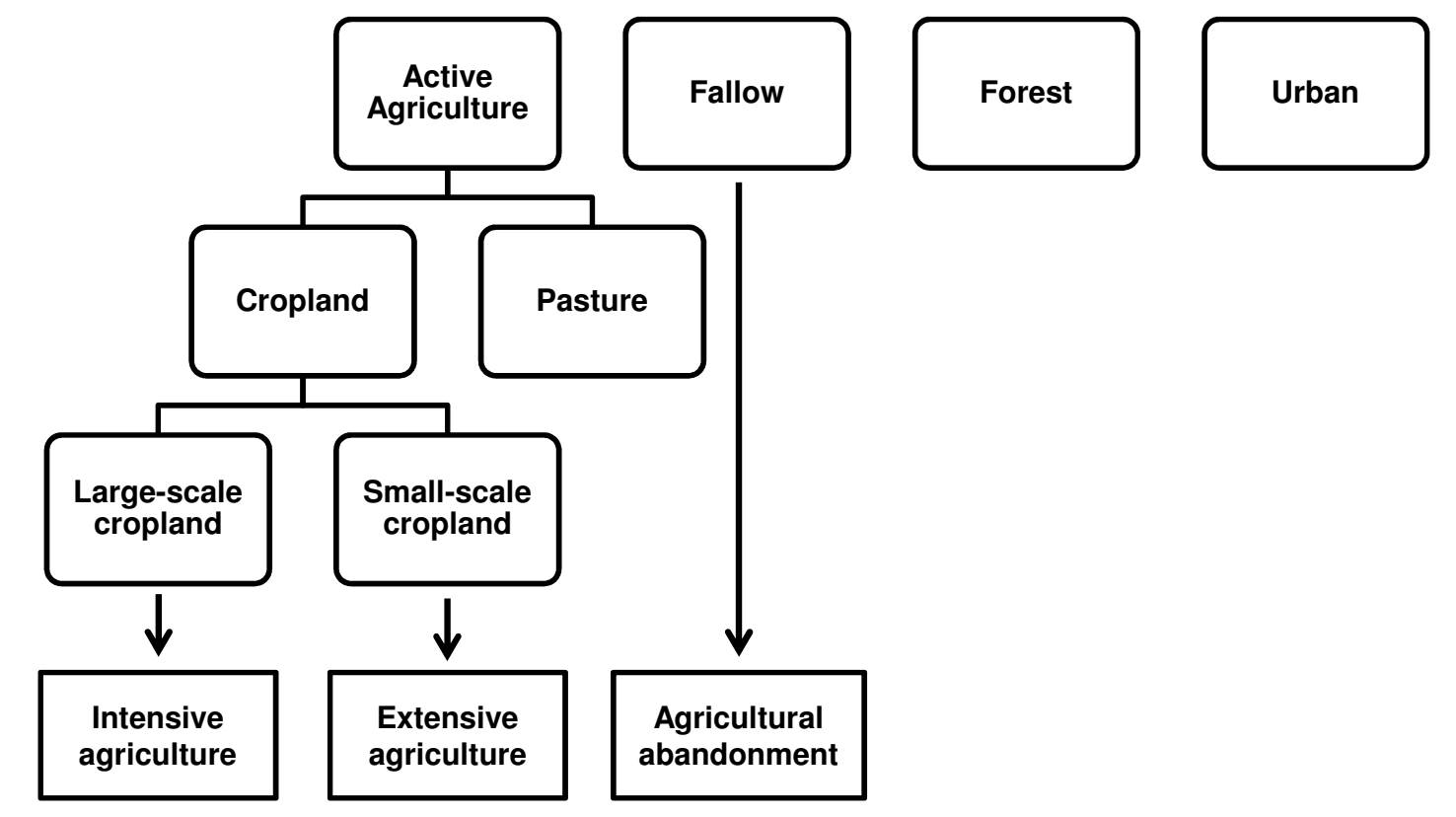

\subsection{Accuracy Assessment}

We assessed our results by using a randomly clustered field-based validation set. Validation points were fully independent from the training data. We calculated confusion matrices, producer's, user's, and overall accuracies, and corrected mapped areas for classification errors in the error estimates [85,86]. To quantitatively evaluate the classification, error-adjusted area estimates with $95 \%$ confidence intervals 
were calculated by using a poststratified estimator [86]. To assess whether our classifications were statistically significantly different from each other, we performed a McNemar test [87].

\subsection{Exploring Spatial Patterns in Land Management Regimes}

To further explore the spatial pattern of land management intensity regimes in our study area, we overlay our final classification result with a number of spatial indicators related to the marginality of farming. First, we analyzed if there were spatial correlation between the classes large-scale cropland, small-scale cropland, pasture, fallow, and forest on the one hand and the quality of the soil for farming on the other hand. To do so, we used a soil map to calculate the ratio of each class to the underlying soil type (Figure 4). The occurring soil types were: histosols (marshy area; not attractive for agriculture), leptosols (stony, chalky; not suitable for agriculture), podzol (sandy, nutrient-poor, acidic soils; not attractive for agriculture), phaeozems (dark humus, fertile soil; very attractive for agriculture), and chernozems (black soil, rich in organic matter; very attractive for agriculture) [88].

Figure 4. Map showing the distribution of soil in our study area.

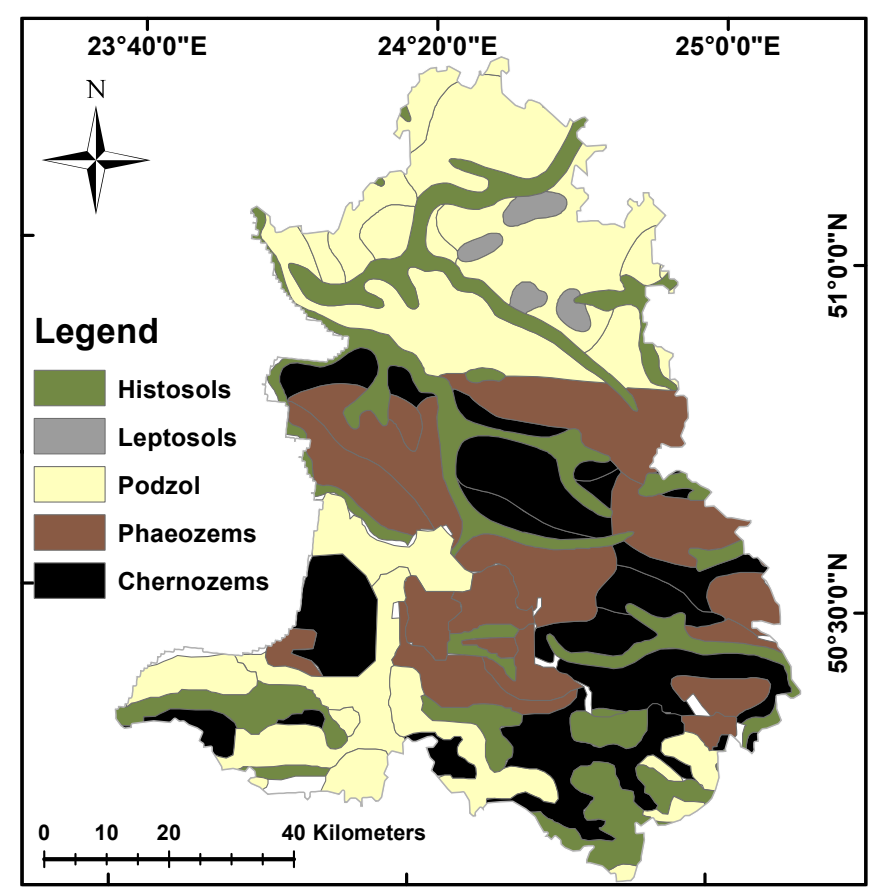

Second, to reveal the spatial relationships between our land management classes and market access (or in other words the remoteness of an agricultural plot), we analyzed the proportion of each management regime in several buffer zones around the cities. To do so, the proportion of the different agricultural classes were summarized in buffer zones with the Euclidean distances of 0.5, 1, 2, 4, 6, 8, and $10 \mathrm{~km}$ from the city boundaries.

Third, we analyzed the distribution of each class in relation to elevation by overlaying the management regimes and other land cover classes with the digital elevation model based on the SRTM. 


\section{Results}

We used three classification approaches-(1) pixel-based (Landsat); (2) object-based (Landsat); and (3) hierarchical object-based (Landsat + ERS) — to map land management intensity regimes. Generally, our classifications showed the substantial potential of improved characterizations of land management regimes when using multispectral and SAR data jointly in a hierarchical framework (Table 2). The overall accuracy of the pixel-based classification (67.4\%) was increased markedly in the object-based classification (78.3\%). The hierarchical classification, integrating Landsat and ERS data as well as object-based features, outperformed both other approaches in terms of the classification accuracy $(83.4 \%)$.

Table 2. Accuracy assessment: comparison of pixel-based, object-based and hierarchical classification (PA = producer's accuracy, UA = user's accuracy, OA = overall accuracy) with error-adjusted estimates [86].

\begin{tabular}{|c|c|c|c|c|c|c|}
\hline \multirow{2}{*}{ LS Classes } & \multicolumn{2}{|c|}{ Pixel-Based } & \multicolumn{2}{|c|}{ Object-Based } & \multicolumn{2}{|c|}{ Hierarchical } \\
\hline & PA (\%) & UA (\%) & PA (\%) & UA (\%) & PA (\%) & UA (\%) \\
\hline LSC & 51.6 & 70.8 & 85.4 & 89.0 & 85.1 & 89.7 \\
\hline SSC & 73.2 & 43.3 & 92.5 & 56.3 & 91.8 & 71.4 \\
\hline Pasture & 56.5 & 55.0 & 74.3 & 56.6 & 62.5 & 65.9 \\
\hline Fallow & 67.3 & 69.4 & 58.0 & 81.9 & 74.0 & 79.2 \\
\hline Forest & 96.8 & 95.1 & 92.3 & 96.1 & 94.1 & 96.2 \\
\hline Urban & 54.5 & 76.9 & 29.5 & 77.8 & 63.2 & 80.0 \\
\hline $\mathrm{OA}$ & $67.4 \%$ & & $78.3 \%$ & & $83.4 \%$ & \\
\hline
\end{tabular}

The confusion matrix of the pixel-based classification indicated the difficulty to classify large-scale cropland (LSC) and small-scale cropland (SSC) solely on pixel-level due to spectral ambiguities (i.e., field size cannot reliably be differentiated spectrally) (Table 3). Furthermore, there was a noticeable confusion within active agriculture (LSC, SSC, pasture) as well as between active agriculture and fallow agriculture. This caused relatively low producer's and user's accuracies for the agricultural classes in the pixel-based classification (Table 2).

Table 3. Confusion matrix for the pixel-based classification of LS.

\begin{tabular}{cccccccc}
\hline \multirow{2}{*}{ Classified } & \multicolumn{7}{c}{ Reference } \\
\cline { 2 - 8 } & LSC & SSC & Pas. & Fal. & For. & Urb. & Tot. \\
\hline LSC & 34 & 4 & 5 & 3 & 1 & 1 & 48 \\
SSC & 23 & 29 & 5 & 6 & & 4 & 67 \\
Pasture & 7 & 2 & 22 & 9 & & & 40 \\
Fallow & 23 & 4 & 5 & 75 & 1 & & 108 \\
Forest & 1 & & 1 & 2 & 77 & & 81 \\
Urban & 1 & 2 & & & & 10 & 13 \\
\hline Total & 89 & 41 & 38 & 95 & 79 & 15 & 357 \\
\hline
\end{tabular}


The object-based classification reduced the confusion between $L S C$ and $S S C$ as well as the fallow class substantially (Table 4). Specifically, the misclassification of SSC within LSC was reduced from $25.8 \%$ to $10.1 \%$ and the misclassification of fallow within $L S C$ from $25.8 \%$ to $5.6 \%$. As a result, the producer's accuracy of $L S C$ increased by about $34 \%$ from $51.6 \%$ to $85.4 \%$ and the user's accuracy of $L S C$ rose by about $20 \%$ to $89.0 \%$. Similar improvements between the pixel-based and object-based classification were observed for the producer's accuracies of SSC and pasture. However, there was still considerable remaining confusion between fallow and SSC as well as pasture. Thus, the producer's accuracy of fallow as well as the user's accuracy of SSC and pasture were still relatively low at about $56.0 \%$ (Table 2).

Table 4. Confusion matrix for the object-based classification of LS.

\begin{tabular}{cccccccc}
\hline \multirow{2}{*}{ Classified } & \multicolumn{7}{c}{ Reference } \\
\cline { 2 - 8 } & LSC & SSC & Pas. & Fal. & For. & Urb. & Tot. \\
\hline LSC & 73 & & & 4 & 3 & 2 & 82 \\
SSC & 9 & 36 & 2 & 11 & & 6 & 64 \\
Pasture & 2 & 2 & 30 & 19 & & & 53 \\
Fallow & 5 & 2 & 5 & 59 & 1 & & 72 \\
Forest & & & 1 & 2 & 74 & & 77 \\
Urban & & 1 & & & 1 & 7 & 9 \\
\hline Total & 89 & 41 & 38 & 95 & 79 & 15 & 357 \\
\hline
\end{tabular}

With the use of additional SAR data within the hierarchical classification framework, the detection of fallow areas was improved substantially, which consequently reduced the confusion between SSC and pasture (Table 5). This led to an increase in the producer's accuracy of fallow (74.0\%) as well as the user's accuracies of SSC (71.4\%) and pasture (65.9\%) (Table 2).

Table 5. Confusion matrix for the hierarchical classification of LS.

\begin{tabular}{cccccccc}
\hline \multirow{2}{*}{ Classified } & \multicolumn{7}{c}{ Reference } \\
\cline { 2 - 8 } & LSC & SSC & Pas. & Fal. & For. & Urb. & Tot. \\
\hline LSC & 70 & 1 & 2 & 2 & 2 & 1 & 78 \\
SSC & 7 & 35 & 2 & 4 & & 1 & 49 \\
Pasture & & 3 & 27 & 11 & & & 41 \\
Fallow & 12 & & 6 & 76 & 1 & 1 & 96 \\
Forest & & & 1 & 2 & 75 & & 78 \\
Urban & & 2 & & & 1 & 12 & 15 \\
\hline Total & 89 & 41 & 38 & 95 & 79 & 15 & 357 \\
\hline
\end{tabular}

Tests of statistical significance based on the McNemar statistics indicated that the object-based classification resulted in a significantly more accurate map $(p<0.001)$ compared to the pixel-based classification (Table 6). The hierarchical classification performed well with regard to the classification 
accuracy, resulting in an overall accuracy that was significantly higher in comparison to the pixel-based $(p<0.001)$ and object-based $(p<0.05)$ approach. (Table 6$)$.

Table 6. Results of McNemar's tests for the statistical significance of differences between the pixel-based, object-based, and hierarchical classification approaches.

\begin{tabular}{cccc}
\hline \multicolumn{2}{c}{ Methods } & $|\mathbf{z}|$ & $\boldsymbol{p}$ \\
\hline Pixel-based & Object-based & 3.41 & $<0.001$ \\
Pixel-based & Hierarchical & 5.18 & $<0.001$ \\
Object-based & Hierarchical & 2.07 & $<0.05$ \\
\hline
\end{tabular}

The map of land management regimes and land cover of our study area showed a heterogeneous landscape with mainly forest and fallow in the northern part of Volodymyr-Volynskyi Raion and the southern part of Sokalskyi (Figure 5). Ivanychivskyi and Horokhivskyi in the center of the study area were mainly covered by active farmland. Pasture was mostly concentrated in the northern, southern, and western central part of the study area. The SSC, mainly subsistence agriculture, can contain individual houses or small villages, since urban represented cities with wide impervious surfaces and large urban structures. Consequently, the majority of the urban population lived in the big cities solely located in the western part of the study area while rural populations were concentrated in the central and eastern parts of the study area.

According to the error-adjusted area estimates (Figure 6), our study area was mostly covered by large-scale cropland $(29 \%, \approx 190,000$ ha). Small-scale cropland covered $15 \%(\approx 94,000$ ha) and pasture $12 \%(\approx 77,000 \mathrm{ha})$. Therefore, the agricultural categories with active land use occupied approximately $53 \%$ of the study area, whereas about $22 \%(\approx 141,000$ ha) of the study area was fallow land. Forests accounted for about $20 \%$ of the study area and the cities covered about $2 \%$ of the study region.

Comparing the distribution of land management regimes and land cover types along indicators of the marginality of agriculture revealed interesting patterns. Soil quality is a key element for agricultural productivity. As expected, our analysis revealed that the majority of large-scale cropland and small-scale cropland was cultivated in areas with comparatively good soils (Figure 7). About 54\% of the LSC was cultivated on Phaeozems (28\%) and Chernozems (25\%). Even $60 \%$ of SSC occurred on Phaeozems and Chernozems. Forest, pasture and fallow areas were mainly located on Podzols ( $>40 \%)$, the sum of these classes on Phaeozems or Chernozems was below $20 \%$.

The distribution of each class also varied substantially with distance to cities (Figure 8). The areas very close to the cities $(0.5 \mathrm{~km})$ in the study area contained over $25 \%$ of $S S C$ and only about $13 \%$ of $L S C$, $4 \%$ pasture, and $6 \%$ fallow. With an increasing distance to cities (and thus local markets), SSC decreased while the share of $L S C$ and pasture increased steadily. The dominance of land management regimes near cities changed from small-scale cropland to large-scale cropland between 2 and $4 \mathrm{~km}$ away from cities. Fallow areas increased rapidly up to a distance of $4 \mathrm{~km}$ around cities.

Analyzing the distribution of our land management and land cover classes along elevation gradients showed interesting differences between the land management regimes (Figure 9). The active farmland classes ( $L S C$ and SSC) had their peaks at about 220 meter elevation, whereby LSC was more equally 
distributed compared to SSC. Pasture, fallow, and forest occurred mainly at elevations between 180 and $200 \mathrm{~m}$, whereby pasture and fallow were similarly distributed.

Figure 5. Agricultural land management regimes and additional land cover classes, mapped using the hierarchical classification based on Landsat and ERS data (LSC = large-scale cropland, SSC = small-scale cropland).

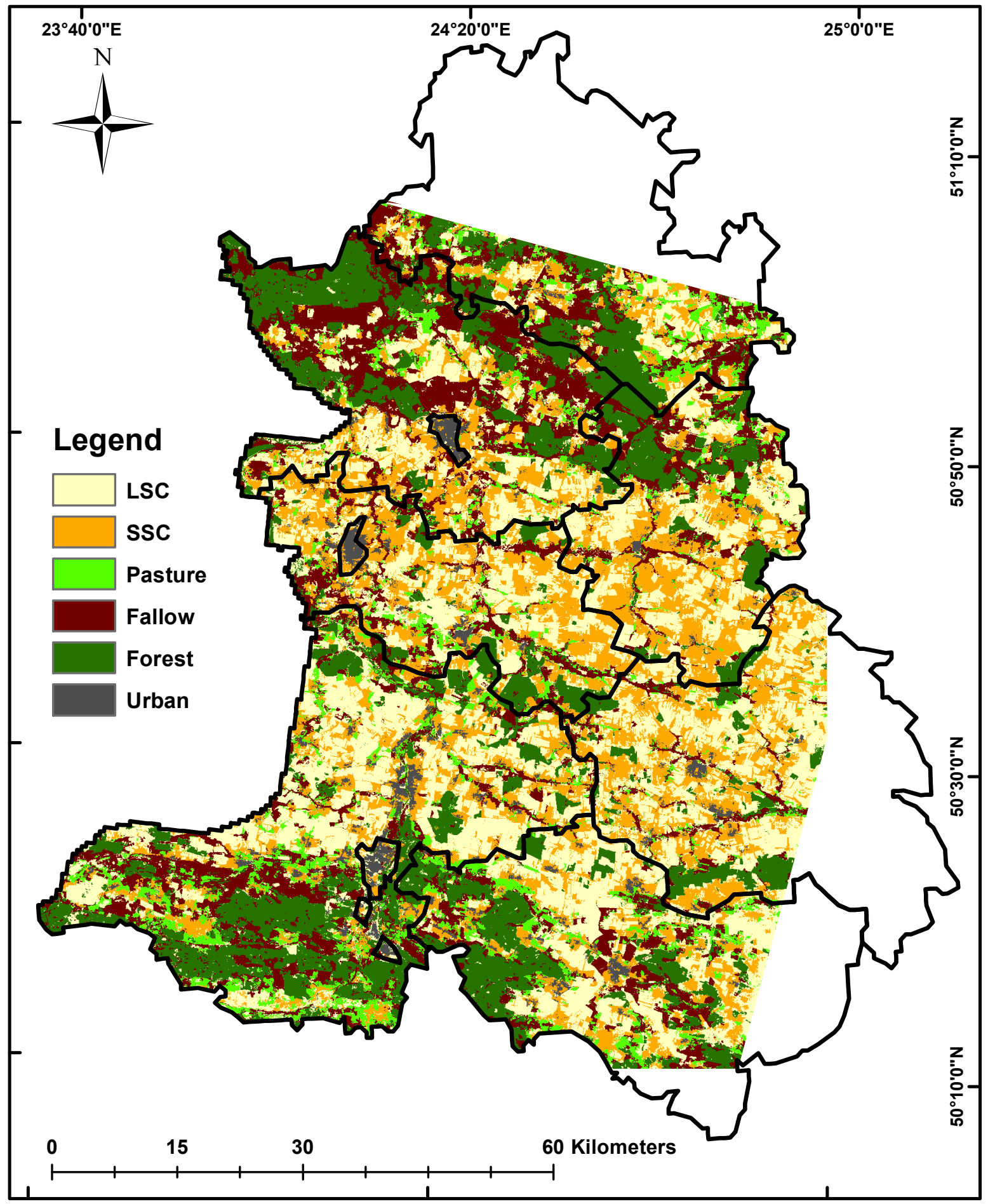


Figure 6. Error-adjusted area estimates of the hierarchical classification with 95\% confidence intervals $(\mathrm{LSC}=$ large-scale cropland, $\mathrm{SSC}=$ small-scale cropland).

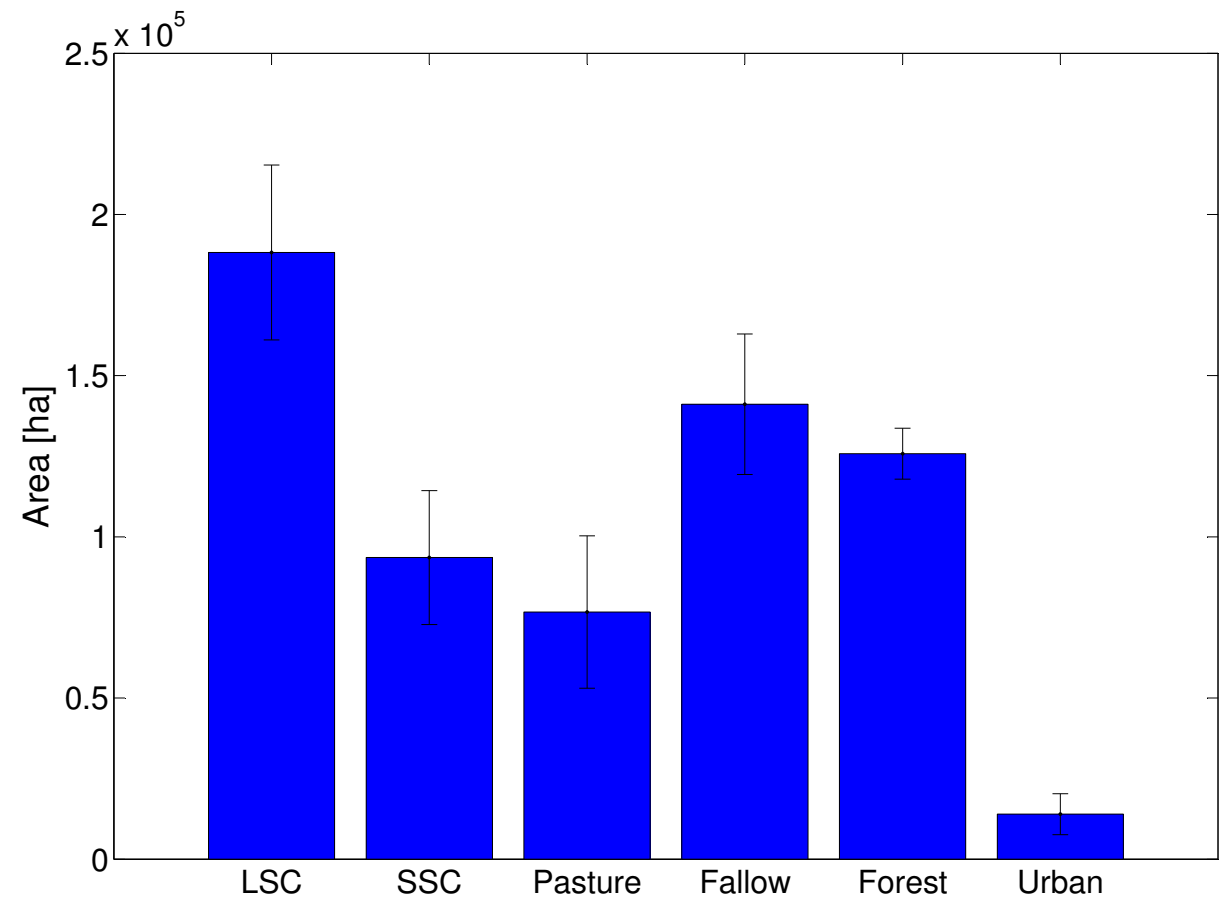

Figure 7. Distribution of the area of each class across underlying soil types (H: Histosols, L: Leptosols, Pod: Podzol, Phae: Phaeozems, Ch: Chernozems).
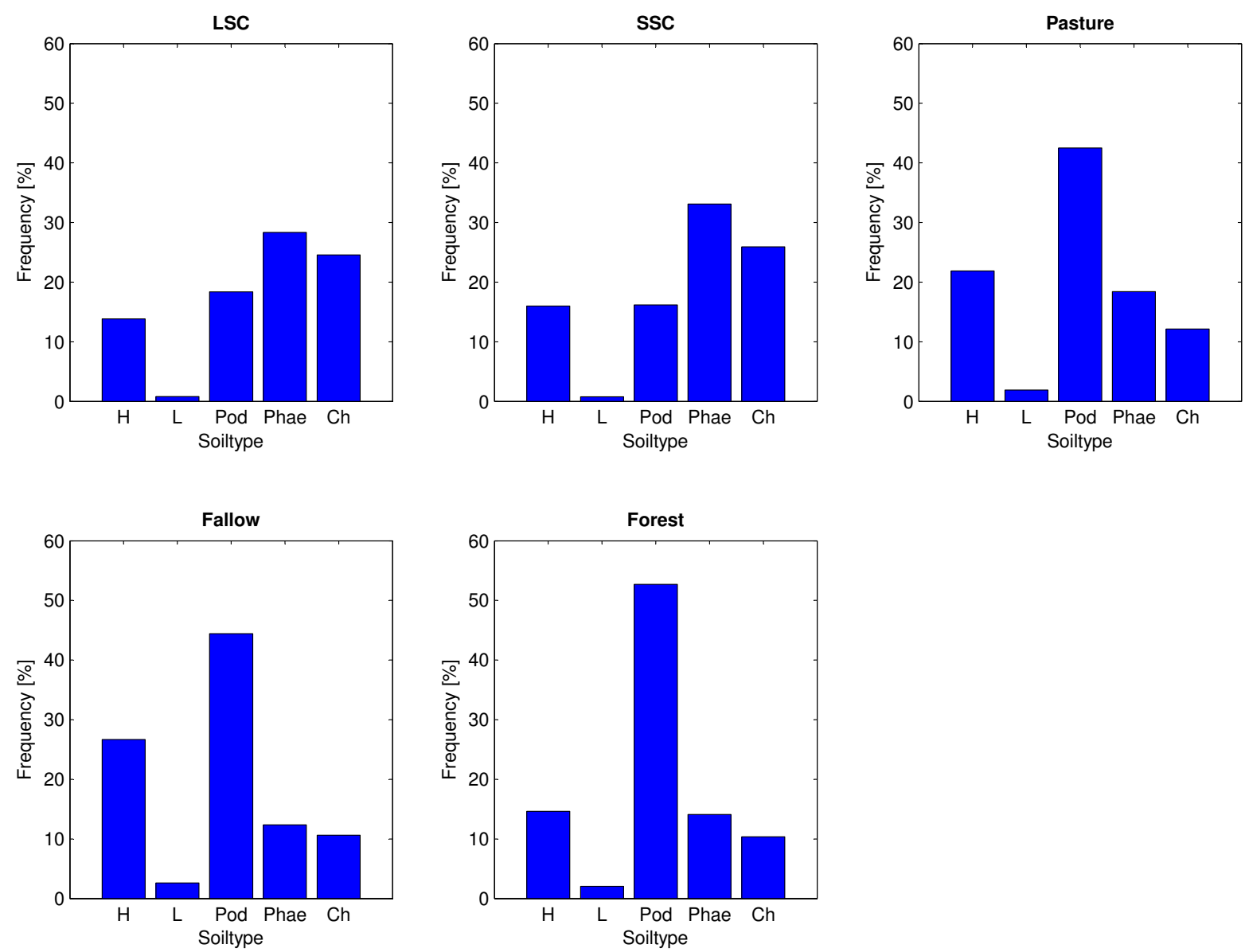
Figure 8. Distribution of the agricultural classes in dependency of the distance to cities.

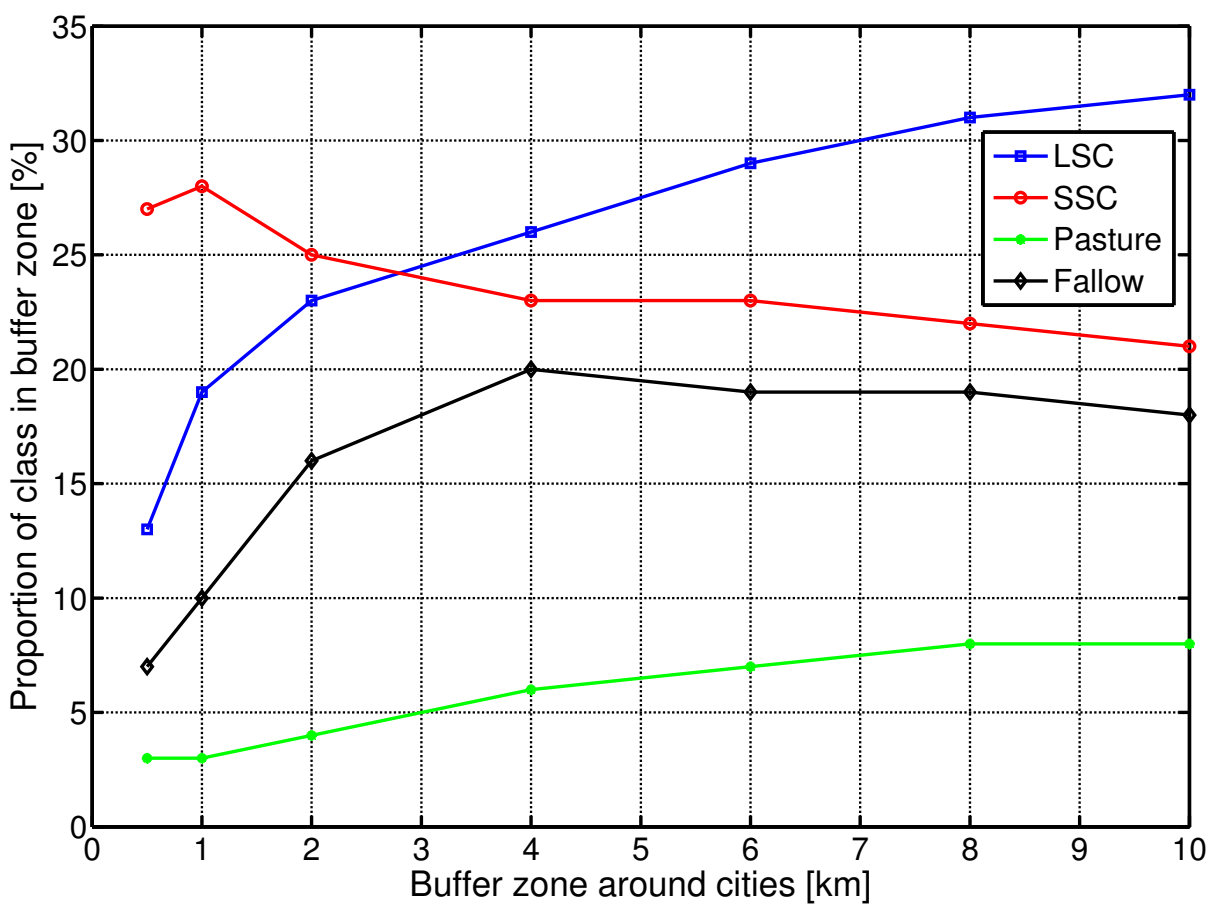

Figure 9. Histogram showing the distribution of each class in dependency of the elevation; Grey lines show the overall distribution of the elevation in the study area.
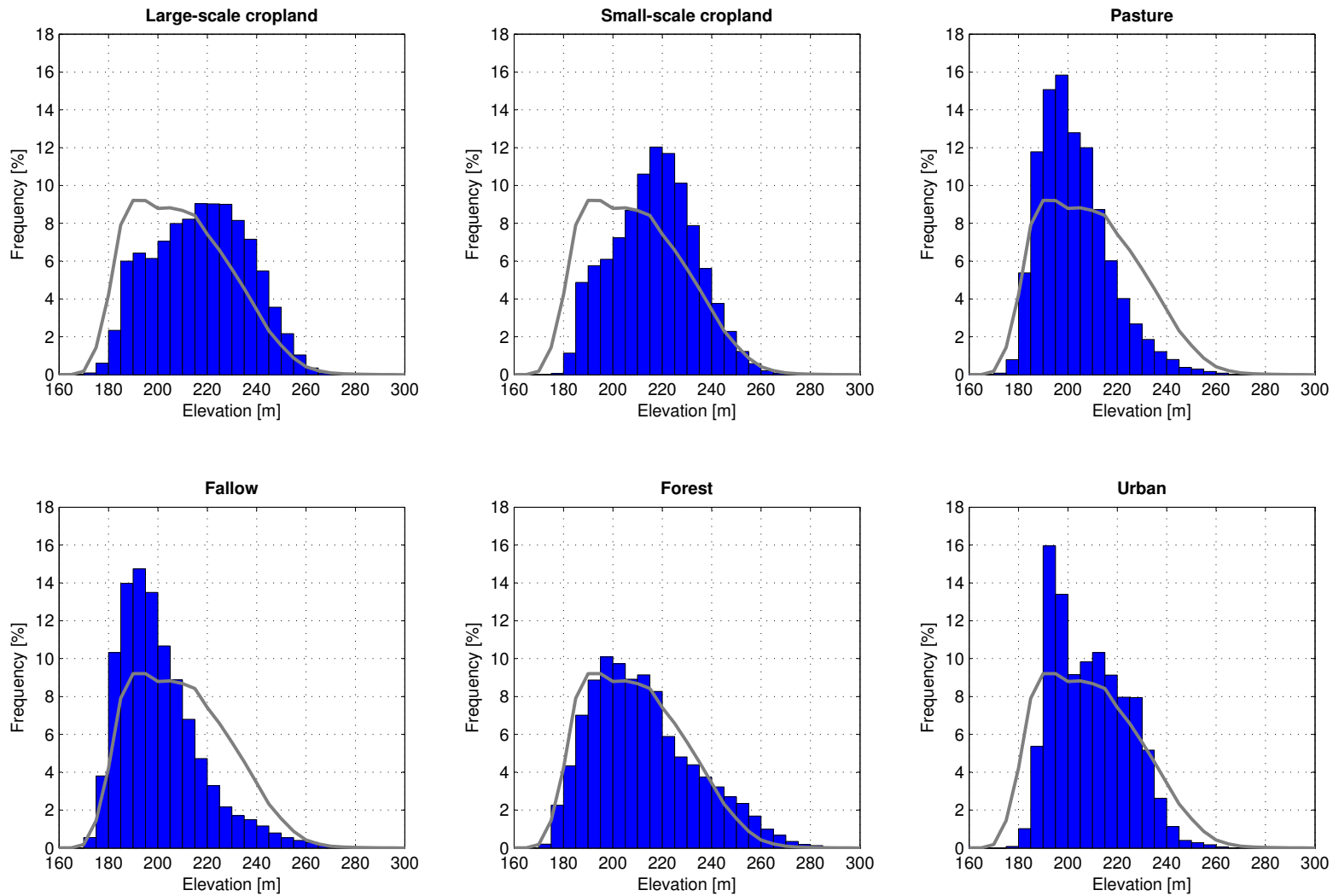


\section{Discussion}

A growing world population, diet changes, and an increasing role of bioenergy all contribute to a surging demand for agricultural products, and unless major shifts in consumptive behavior occur, this requires potentially a doubling of agricultural production by 2050 [12,13,89-91]. Production increases can be achieved following three options: (1) expanding agriculture into natural ecosystems; (2) intensifying existing farmland; or (3) recultivating abandoned farmland. To decide which strategy is attractive to increase production while mitigating the environmental trade-offs of agriculture, first and foremost it is important to better map and understand spatial heterogeneity in agricultural management intensity, ranging from industrialized to abandoned lands. Mapping agricultural management regimes such as large-scale cropland, and small-scale cropland (indicating high and low management intensity, respectively), and fallow land with remote sensing data provides interesting avenues to improve our understanding of the patterns of agricultural land use intensity, particularly where ground-data on the different aspects of management are scarce.

Our first objective was to analyze the value of an object-based approach in comparison with a pixel-based classification to map land management regimes. Our analyses clearly showed that the pixel-based approach was not capable of differentiating large-scale cropland and small-scale cropland with high accuracies (Table 2), likely because of similar spectral characteristics of these classes. In our case, additional object-based features from a multilevel segmentation with different segment scales helped to overcome this problem. The spatial relationships and the different features within the segments provided information about (1) relatively homogenous large fields with one crop type and (2) small fields with inhomogeneous spectral characteristics due to multiple crops within a cluster of kitchen gardens, which is not included in pixel-by-pixel information. Therefore, multilevel object-based features were the key elements to distinguish large and small fields, and thus large-scale cropland and small-scale cropland in our study area.

Our second objective was to assess the value of SAR data (ERS-2 images in our case) within a hierarchical classification framework to enhance the mapping of land management regimes compared to using optical data (Landsat images in our case) alone. As we already noted, pasture and fallow fields can have similar spectral signatures as well as spatial similarities contrary to large-scale cropland and small-scale cropland. Therefore, the object-based approach, which was based on the optical data alone, did not noticeably improve the classification accuracy of pasture and fallow land in comparison to the pixel-based classification. However, the integration of SAR data within the hierarchical classification approach did appreciably improve the classification accuracies of both classes. This was likely due to two reasons. On the one hand, SAR data included complementary information to optical data. On the other hand, additional temporal information of SAR data (i.e., nine available scenes over the year), which enabled an enhanced extraction of information about different phenological stages of pasture and fallow, likely contributed to the higher classification accuracies, when using optical and SAR data jointly.

In general our results emphasize that the integration of both sources, i.e., multisensor data as well as object-based features from different scales, proved useful in terms of the mapping accuracy. This is in accordance with the results achieved by other studies [62-64], for example, where crop type mapping was enhanced by classifying multiple segmentation levels from SAR and multispectral data [63]. 
The algorithms that were used in our study proved to be well suited for mapping land management regimes. The Superpixel Contour algorithm was able to separate the Landsat images into meaningful regions, as the visual inspection and the significant improvement of the classification accuracies by the generated objects confirmed. This is also in accordance with the results achieved by Stefanski et al. (2013) [44], where the Superpixel Contour algorithm was analyzed in more detail. The Random Forest classifier also performed very well, as it was already shown in previous studies (e.g., $[63,79,92])$, and seems adequate for handling multisensor data as well as different multilevel features.

Our third objective was to explore the spatial distribution of land management regimes. Generally, the patterns observed in our study region were well in accordance with patterns that we would predict based on classical land rent theory [93,94]-i.e., less intensive or no land use on the most marginal plots (higher elevations, less suitable soils, far away from markets). Interestingly, small-scale cropland was most widespread in the vicinity of cities (Figure 8), whereas large-scale agriculture (i.e., potentially more capital intensive) was found away from cities. Two factors explain this pattern. First, during the Soviet time, large industrialized farms were established and these were often far away from settlements and cities. Second, with the breakdown of the Soviet Union, subsistence agriculture became more important and thus farmland in the vicinity of cities was used for small-scale farming and gardening, explaining the concentration of small-scale cropland close to the cities.

The pattern of the class distribution with regard to elevation can be explained by the local topography. Large-scale cropland and small-scale cropland is basically concentrated in the center of the study area, where the elevation is higher compared to the north and south, where pasture, fallow, and forest occurred mainly. The occurrence of farmland abandonment in Eastern Europe on lower elevations was surprising, and on first glance not in line with land rent theory. However, other studies [68] have found similar patterns and the factors mentioned above (i.e., collapse of large corporate farms after the breakdown of the Soviet Union, concentration of farming around settlements) explain these patterns as well. Furthermore, some of the lower areas in our study region are frequently flooded (especially as drainage dikes were abandoned), making these areas not well-suited for agriculture.

Earlier studies have found substantial potential for recultivation in the region [68]. Our results suggest-about $22 \%$ of the whole study area was fallow in 2010-some potential for recultivation of abandoned farmland. However, advanced processes of forest succession (i.e., high amount of woodland) causes increasing recultivation costs [95]. In this context, the additional use of approaches that quantify succession seems sensible [96]. About $15 \%$ of the study area was small-scale cropland with low intensive farming, which suggests some potential for agricultural intensification. We caution though, that the socio-economic and environmental impacts of intensification, and recultivating currently idle cropland, have to be taken into account carefully.

Our study demonstrated that agricultural management regimes can be reliably determined from remote sensing imagery alone when field size can be used as a proxy, which is an important finding given that ground data on management practices is not available for large parts of the world $[15,16]$. Nevertheless, several avenues for further improving our approach are possible. First, auxiliary data may be capable of improving the precision of area estimates. For example, spatial relationships can contribute to classify land management regimes more accurately or population density data may be useful to improve the precision of land cover change estimation [97]. In this context, non-parametric 
methods that can deal with continues and categorical data like Random Forests appear to be appropriate to integrate and classify diverse datasets, including multisensor data, terrain models, or categorical variables, for example, derived from soil maps [78].

Second, ground data on management or yields could further help to generate a better map of intensity, whereby geostatistical approaches are suitable to integrate such data. Analyzing management regimes over several years may also further improve the precision of mapping management regimes. For example, using previous analyses as prior knowledge or prior probabilities may improve mapping accuracies [98].

Third, auxiliary data can be used to avoid misinterpretations of land management regimes maps. For example, Figure 6 implied that $22 \%$ of the study area was fallow and therefore this region should offer great potential for recultivation. However, analyzing the proportion of fallow land regarding its underlying soil type revealed that $45 \%$ of the fallow areas were on Podzol (Figure 7). As Podzols are generally less attractive soils for cropping due to the low nutrient status, low level of available moisture, and low $\mathrm{pH}$ values [88], realistic potentials for recultivation in this region have to be further analyzed.

\section{Conclusions}

Our study aimed at mapping land management regimes as proxies for agricultural land use intensity from satellite imagery. To do so, we compared pixel-based, object-based, and hierarchical classification approaches using Superpixel Contour for segmentation and Random Forests for classification. The proposed classification strategy constitutes a very feasible approach, because the underlying methods (Superpixel Contour/Random Forest) depend only on a few parameters. The object-based approach produced significantly better classification accuracies compared to the pixel-based approach. The hierarchical, multisensor classification based on Landsat and SAR data outperformed both other approaches and yielded a reliable land management intensity regime map.

As demand for agricultural products continues to increase and land resources are increasingly becoming scarce, identifying strategies for increasing agricultural production in sustainable ways has become a research priority and this necessitates better maps on land management. We emphasize the value of our hierarchical multi-sensor approach for mapping land management regimes, as we derive adequate indicators for land use intensity by remote sensing for our study area. This can be a first step to further evaluate trade-offs and benefits from different management regimes as well as methods to systematically asses potentials for increasing agricultural production. The use of auxiliary data as soil maps enable more detailed analysis of the spatial patterns and supports to evaluate the potential of agriculture and recultivation of abandoned farmland in western Ukraine.

Overall, our methodology contributes to new methods for mapping land use intensity, using multisensor remote sensing data. Regarding recent and upcoming missions with increased revisit times and better spatial resolutions as, for example, RapidEye and TerraSAR-X as well as Sentinel-1/-2, the use of multisensor data become even more attractive. In addition, it seems interesting to make full sense of the unique image record that the Landsat image archives provide. 


\section{Acknowledgments}

This work was supported by the German Research Foundation (DFG-WA 2728/2-1; WA 2728/2-2) and the State Fund of Fundamental Research of Ukraine (N 0113U002752). ERS data was provided by ESA (C1P.10962). RapidEye data was provided from the RapidEye Science Archive (RESA) by DLR under the proposal id490.

\section{Author Contributions}

Jan Stefanski wrote the manuscript and was responsible for research design, data preparation and analysis. All authors contributed in an extensive field campaign for data collection and supported by general discussions about the study. Oleh Chaskovskyy provided some of the data and gave relevant information about the study site. Tobias Kuemmerle and Björn Waske, who is the PI of the DFG project, provided significant input to research design and contributed in editing and reviewing the manuscript.

\section{Conflicts of Interest}

The authors declare no conflict of interest.

\section{References}

1. Foley, J.; Defries, R.; Asner, G.; Barford, C.; Bonan, G.; Carpenter, S.; Chapin, F.; Coe, M.; Daily, G.; Gibbs, H.; et al. Global consequences of land use. Science 2005, 309, 570-574.

2. Turner, B.L.; Lambin, E.F.; Reenberg, A. Land change science special feature: The emergence of land change science for global environmental change and sustainability. Proc. Natl. Acad. Sci. USA 2007, 104, 20666-20671.

3. Goldewijk, K.K. Estimating global land use change over the past 300 years: The HYDE database. Glob. Biogeochem. Cycles 2001, 15, 417-433.

4. Food and Agriculture Organization (FAO). Global Forest Resources Assessment 2005. Progress towards Sustainable Forest Management; FAO: Rome, Italy, 2006; Volume 147.

5. Siebert, S.; Portmann, F.T.; Döll, P. Global patterns of cropland use intensity. Remote Sens. 2010, 2, 1625-1643.

6. Ellis, E.; Kaplan, J.; Fuller, D.; Vavrus, S.; Goldewijk, K.; Verburg, P. Used planet: A global history. Proc. Natl. Acad. Sci. USA 2013, 110, 7978-7985.

7. Erb, K.H.; Haberl, H.; Jepsen, M.R.; Kuemmerle, T.; Lindner, M.; Müller, D.; Verburg, P.H.; Reenberg, A. A conceptual framework for analysing and measuring land-use intensity. Curr. Opin. Environ. Sustain. 2013, 5, 464-470.

8. Matson, P.A.; Parton, W.J.; Power, A.G.; Swift, M.J. Agricultural intensification and ecosystem properties. Science 1997, 277, 504-509.

9. Rounsevell, M.D.; Pedroli, B.; Erb, K.H.; Gramberger, M.; Busck, A.G.; Haberl, H.; Kristensen, S.; Kuemmerle, T.; Lavorel, S.; Lindner, M.; et al. Challenges for land system science. Land Use Policy 2012, 29, 899-910. 
10. Brooks, T.M.; Mittermeier, R.A.; Mittermeier, C.G.; da Fonseca, G.A.B.; Rylands, A.B.; Konstant, W.R.; Flick, P.; Pilgrim, J.; Oldfield, S.; Magin, G.; et al. Habitat loss and extinction in the hotspots of biodiversity. Conserv. Biol. 2002, 16, 909-923.

11. Lambin, E.F.; Meyfroidt, P. Inaugural article: Global land use change, economic globalization, and the looming land scarcity. Proc. Natl. Acad. Sci. USA 2011, 108, 3465-3472.

12. Godfray, H.C.J.; Beddington, J.R.; Crute, I.R.; Haddad, L.; Lawrence, D.; Muir, J.F.; Pretty, J.; Robinson, S.; Thomas, S.M.; Toulmin, C. Food security: The challenge of feeding 9 billion people. Science 2010, 327, 812-818.

13. Foley, J.A.; Ramankutty, N.; Brauman, K.A.; Cassidy, E.S.; Gerber, J.S.; Johnston, M.; Mueller, N.D.; O’Connell, C.; Ray, D.K.; West, P.C.; et al. Solutions for a cultivated planet. Nature 2011, 478, 337-342.

14. Mueller, N.D.; Gerber, J.S.; Johnston, M.; Ray, D.K.; Ramankutty, N.; Foley, J.A. Closing yield gaps through nutrient and water management. Nature 2012, 490, 254-257.

15. Kuemmerle, T.; Erb, K.; Meyfroidt, P.; Müller, D.; Verburg, P.H.; Estel, S.; Haberl, H.; Hostert, P.; Jepsen, M.R.; Kastner, T.; et al. Challenges and opportunities in mapping land use intensity globally. Curr. Opin. Environ. Sustain. 2013, 5, 484-493.

16. Fritz, S.; See, L.; You, L.; Justice, C.; Becker-Reshef, I.; Bydekerke, L.; Cumani, R.; Defourny, P.; Erb, K.; Foley, J.; et al. The need for improved maps of global cropland. EOS, Trans. Am. Geophys. Union 2013, 94, 31-32.

17. Rudorff, B.F.T.; de Aguiar, D.A.; da Silva, W.F.; Sugawara, L.M.; Adami, M.; Moreira, M.A. Studies on the rapid expansion of sugarcane for ethanol production in São Paulo State (Brazil) using Landsat data. Remote Sens. 2010, 2, 1057-1076.

18. Skriver, H.; Mattia, F.; Satalino, G.; Balenzano, A.; Pauwels, V.; Verhoest, N.; Davidson, M. Crop classification using short-revisit multitemporal SAR data. IEEE J. Sel. Top. Appl. Earth Obs. Remote Sens. 2011, 4, 423-431.

19. Atzberger, C. Advances in remote sensing of agriculture: Context description, existing operational monitoring systems and major information needs. Remote Sens. 2013, 5, 949-981.

20. Sieber, A.; Kuemmerle, T.; Prishchepov, A.V.; Wendland, K.J.; Baumann, M.; Radeloff, V.C.; Baskin, L.M.; Hostert, P. Landsat-based mapping of post-Soviet land-use change to assess the effectiveness of the Oksky and Mordovsky protected areas in European Russia. Remote Sens. Environ. 2013, 133, 38-51.

21. Li, P.; Feng, Z.; Jiang, L.; Liao, C.; Zhang, J. A review of Swidden agriculture in Southeast Asia. Remote Sens. 2014, 6, 1654-1683.

22. Alcantara, C.; Kuemmerle, T.; Prishchepov, A.V.; Radeloff, V.C. Mapping abandoned agriculture with multi-temporal MODIS satellite data. Remote Sens. Environ. 2012, 124, 334-347.

23. Souza, C., Jr.; Siqueira, J.; Sales, M.; Fonseca, A.; Ribeiro, J.; Numata, I.; Cochrane, M.; Barber, C.; Roberts, D.; Barlow, J. Ten-year Landsat classification of deforestation and forest degradation in the Brazilian Amazon. Remote Sens. 2013, 5, 5493-5513.

24. Turner, B.L.; Doolittle, W.E. The concept and measure of agricultural intensity. Prof. Geogr. 1978, 30, 297-301. 
25. Kleijn, D.; Kohler, F.; Baldi, A.; Batary, P.; Concepcion, E.; Clough, Y.; Diaz, M.; Gabriel, D.; Holzschuh, A.; Knop, E.; et al. On the relationship between farmland biodiversity and land-use intensity in Europe. Proc. R. Soc. B: Biol. Sci. 2009, 276, 903-909.

26. Zaks, D.P.M.; Kucharik, C.J. Data and monitoring needs for a more ecological agriculture. Environ. Res. Lett. 2011, 6, 014017.

27. Verburg, P.H.; Neumann, K.; Nol, L. Challenges in using land use and land cover data for global change studies. Glob. Chang. Biol. 2011, 17, 974-989.

28. Ellis, E.C.; Ramankutty, N. Putting people in the map: Anthropogenic biomes of the world. Front. Ecol. Environ. 2008, 6, 439-447.

29. Václavík, T.; Lautenbach, S.; Kuemmerle, T.; Seppelt, R. Mapping global land system archetypes. Glob. Environ. Chang. 2013, 23, 1637-1647.

30. Asselen, S.; Verburg, P.H. A Land System representation for global assessments and land-use modeling. Glob. Chang. Biol. 2012, 18, 3125-3148.

31. Hett, C.; Castella, J.C.; Heinimann, A.; Messerli, P.; Pfund, J.L. A landscape mosaics approach for characterizing swidden systems from a REDD+ perspective. Appl. Geogr. 2012, 32, 608-618.

32. Wästfelt, A.; Tegenu, T.; Nielsen, M.M.; Malmberg, B. Qualitative satellite image analysis: Mapping spatial distribution of farming types in Ethiopia. Appl. Geogr. 2012, 32, 465-476.

33. Killeen, T.J.; Anna, G.; Miki, C.; Lisette, C.; Veronica, C.; Liliana, S.; Belem, Q.; Marc, K.S. Total historical land-use change in Eastern Bolivia: Who, where, when, and how much? Ecol. Soc. 2008, 13, 1-27.

34. Rodriguez, C.; Wiegand, K. Evaluating the trade-off between machinery efficiency and loss of biodiversity-friendly habitats in arable landscapes: The role of field size. Agric. Ecosyst. Environ. 2009, 129, 361-366.

35. Ferguson, M.; Badhwar, G.; Chhikara, R.; Pitts, D. Field size distributions for selected agricultural crops in the United States and Canada. Remote Sens. Environ. 1986, 19, 25-45.

36. Aplin, P.; Atkinson, P.M. Sub-pixel land cover mapping for per-field classification. Int. J. Remote Sens. 2001, 22, 2853-2858.

37. Lloyd, C.D.; Berberoglu, S.; Curran, P.J.; Atkinson, P.M. A comparison of texture measures for the per-field classification of Mediterranean land cover. Int. J. Remote Sens. 2004, 25, 3943-3965.

38. Ozdogan, M.; Woodcock, C.E. Resolution dependent errors in remote sensing of cultivated areas. Remote Sens. Environ. 2006, 103, 203-217.

39. Kuemmerle, T.; Hostert, P.; St-Louis, V.; Radeloff, V.C. Using image texture to map farmland field size: A case study in Eastern Europe. J. Land Use Sci. 2009, 4, 85-107.

40. Yan, L.; Roy, D.P. Automated crop field extraction from multi-temporal Web Enabled Landsat Data. Remote Sens. Environ. 2014, 144, 42-64.

41. Cleve, C.; Kelly, M.; Kearns, F.R.; Moritz, M. Classification of the wildland-urban interface: A comparison of pixel- and object-based classifications using high-resolution aerial photography. Comput. Environ. Urban Syst. 2008, 32, 317-326.

42. Moskal, L.M.; Styers, D.M.; Halabisky, M. Monitoring urban tree cover using object-based image analysis and public domain remotely sensed data. Remote Sens. 2011, 3, 2243-2262. 
43. Whiteside, T.G.; Boggs, G.S.; Maier, S.W. Comparing object-based and pixel-based classifications for mapping savannas. Int. J. Appl. Earth Obs. Geoinf. 2011, 13, 884-893.

44. Stefanski, J.; Mack, B.; Waske, B. Optimization of object-based image analysis with Random Forests for land cover mapping. IEEE J. Sel. Top. Appl. Earth Obs. Remote Sens. 2013, 6, 2492-2504.

45. Dai, X.; Khorram, S. A hierarchical methodology framework for multisource data fusion in vegetation classification. Int. J. Remote Sens. 1998, 19, 3697-3701.

46. Jones, D.A.; Hansen, A.J.; Bly, K.; Doherty, K.; Verschuyl, J.P.; Paugh, J.I.; Carle, R.; Story, S.J. Monitoring land use and cover around parks: A conceptual approach. Remote Sens. Environ. 2009, 113, 1346-1356.

47. Sulla-Menashe, D.; Friedl, M.A.; Krankina, O.N.; Baccini, A.; Woodcock, C.E.; Sibley, A.; Sun, G.; Kharuk, V.; Elsakov, V. Hierarchical mapping of Northern Eurasian land cover using MODIS data. Remote Sens. Environ. 2011, 115, 392-403.

48. Li, Y.; Gong, J.; Wang, D.; An, L.; Li, R. Sloping farmland identification using hierarchical classification in the Xi-He region of China. Int. J. Remote Sens. 2013, 34, 545-562.

49. Cohen, W.; Goward, S. Landsat's role in ecological applications of remote sensing. Bioscience 2004, 54, 535-545.

50. Loveland, T.R.; Cochrane, M.A.; Henebry, G.M. Landsat still contributing to environmental research. Trends Ecol. Evol. 2008, 23, 182-183.

51. Griffiths, P.; Müller, D.; Kuemmerle, T.; Hostert, P. Agricultural land change in the Carpathian ecoregion after the breakdown of socialism and expansion of the European Union. Environ. Res. Lett. 2013, 8, 045024.

52. Kindu, M.; Schneider, T.; Teketay, D.; Knoke, T. Land use/land cover change analysis using object-based classification approach in Munessa-Shashemene Landscape of the Ethiopian Highlands. Remote Sens. 2013, 5, 2411-2435.

53. Woodcock, C.E.; Allen, R.; Anderson, M.; Belward, A.; Bindschadler, R.; Cohen, W.; Gao, F.; Goward, S.N.; Helder, D.; Helmer, E.; et al. Free access to Landsat imagery. Science 2008, 320, doi:10.1126/science.320.5879.1011a.

54. Prishchepov, A.V.; Radeloff, V.C.; Dubinin, M.; Alcantara, C. The effect of Landsat ETM/ETM+ image acquisition dates on the detection of agricultural land abandonment in Eastern Europe. Remote Sens. Environ. 2012, 126, 195-209.

55. Kovalskyy, V.; Roy, D. The global availability of Landsat 5 TM and Landsat 7 ETM+ land surface observations and implications for global $30 \mathrm{~m}$ Landsat data product generation. Remote Sens. Environ. 2013, 130, 280-293.

56. Waske, B.; Braun, M. Classifier ensembles for land cover mapping using multitemporal SAR imagery. ISPRS J. Photogramm. Remote Sens. 2009, 64, 450-457.

57. Bargiel, D.; Herrmann, S. Multi-temporal land-cover classification of agricultural areas in two european regions with high resolution spotlight TerraSAR-X data. Remote Sens. 2011, 3, 859-877.

58. Cable, J.; Kovacs, J.; Shang, J.; Jiao, X. Multi-temporal polarimetric RADARSAT-2 for land cover monitoring in Northeastern Ontario, Canada. Remote Sens. 2014, 6, 2372-2392. 
59. Pohl, C.; van Genderen, J.L. Review article multisensor image fusion in remote sensing: Concepts, methods and applications. Int. J. Remote Sens. 1998, 19, 823-854.

60. Waske, B.; Benediktsson, J. Fusion of support vector machines for classification of multisensor data. IEEE Trans. Geosci. Remote Sens. 2007, 45, 3858-3866.

61. Kuplich, T.; Freitas, C.D.C.; Soares, J. The study of ERS-1 SAR and Landsat TM synergism for land use classification. Int. J. Remote Sens. 2000, 21, 2101-2111.

62. Shupe, S.M.; Marsh, S.E. Cover- and density-based vegetation classifications of the Sonoran Desert using Landsat TM and ERS-1 SAR imagery. Remote Sens. Environ. 2004, 93, 131-149.

63. Waske, B.; van der Linden, S. Classifying multilevel imagery from SAR and optical sensors by decision fusion. IEEE Trans. Geosci. Remote Sens. 2008, 46, 1457-1466.

64. Gong, B.; Im, J.; Mountrakis, G. An artificial immune network approach to multi-sensor land use/land cover classification. Remote Sens. Environ. 2011, 115, 600-614.

65. Griffiths, P.; Hostert, P.; Gruebner, O.; van der Linden, S. Mapping megacity growth with multi-sensor data. Remote Sens. Environ. 2010, 114, 426-439.

66. Kuemmerle, T.; Radeloff, V.C.; Perzanowski, K.; Hostert, P. Cross-border comparison of land cover and landscape pattern in Eastern Europe using a hybrid classification technique. Remote Sens. Environ. 2006, 103, 449-464.

67. Müller, D.; Kuemmerle, T.; Rusu, M.; Griffiths, P. Lost in transition: Determinants of post-socialist cropland abandonment in Romania. J. Land Use Sci. 2009, 4, 109-129.

68. Baumann, M.; Kuemmerle, T.; Elbakidze, M.; Ozdogan, M.; Radeloff, V.C.; Keuler, N.S.; Prishchepov, A.V.; Kruhlov, I.; Hostert, P. Patterns and drivers of post-socialist farmland abandonment in Western Ukraine. Land Use Policy 2011, 28, 552-562.

69. Ioffe, G.; Nefedova, T.; de Beurs, K. Land abandonment in Russia. Eurasian Geogr. Econ. 2012, $53,527-549$.

70. United Nations Environment Programme (UNEP). One Planet Many People: Atlas of Our Changing Environment; Division of Early Warning and Assessment (DEWA), UNEP: Nairobi, Kenya, 2005; p. 320.

71. Kuemmerle, T.; Olofsson, P.; Chaskovskyy, O.; Baumann, M.; Ostapowicz, K.; Woodcock, C.E.; Houghton, R.A.; Hostert, P.; Keeton, W.S.; Radeloff, V.C. Post-Soviet farmland abandonment, forest recovery, and carbon sequestration in western Ukraine. Glob. Chang. Biol. 2011, 17, 1335-1349.

72. Sabates-Wheeler, R. Consolidation initiatives after land reform: Responses to multiple dimensions of land fragmentation in Eastern European agriculture. J. Int. Dev. 2002, 14, 1005-1018.

73. National Oceanic and Atmospheric Administration (NOAA). NCDC (National Climate Data Center), 2011. Available online: http://www.ncdc.noaa.gov/ (accessed on 5 June 2014).

74. State Statistics Committee of Ukraine. All-Ukrainian Population Census 1979-2001; 2001. Available online: http://www.ukrcensus.gov.ua/eng/ (accessed on 5 June 2014).

75. United States Geological Survey (USGS). Landsat Processing Details; 2013. Available online: http://landsat.usgs.gov/Landsat_Processing_Details.php (accessed on 5 June 2014). 
76. EUROSTAT. LUCAS 2009 (Land Use/Cover Area Frame Survey)—Instructions for Surveyors; 2009. Available online: http://epp.eurostat.ec.europa.eu/portal/page/portal/lucas/documents/ LUCAS2009_C1-Instructions_Revised20130925.pdf (accessed on 5 June 2014).

77. Breiman, L. Random Forests. Mach. Learn. 2001, 45, 5-32.

78. Gislason, P.O.; Benediktsson, J.A.; Sveinsson, J.R. Random Forests for land cover classification. Pattern Recogn. Lett. 2006, 27, 294-300.

79. Stumpf, A.; Kerle, N. Object-oriented mapping of landslides using Random Forests. Remote Sens. Environ. 2011, 115, 2564-2577.

80. Rodriguez-Galiano, V.; Chica-Olmo, M.; Abarca-Hernandez, F.; Atkinson, P.; Jeganathan, C. Random Forest classification of Mediterranean land cover using multi-seasonal imagery and multi-seasonal texture. Remote Sens. Environ. 2012, 121, 93-107.

81. Zhu, Z.; Woodcock, C.E.; Rogan, J.; Kellndorfer, J. Assessment of spectral, polarimetric, temporal, and spatial dimensions for urban and peri-urban land cover classification using Landsat and SAR data. Remote Sens. Environ. 2012, 117, 72-82.

82. Mester, R.; Conrad, C.; Guevara, A. Multichannel Segmentation Using Contour Relaxation: Fast Super-Pixels and Temporal Propagation. In Proceedings of the 17th Scandinavian Conference on Image Analysis (SCIA'11), Ystad, Sweden, 23-27 May 2011; Springer-Verlag: Berlin/Heidelberg, Germany, 2011; pp. 250-261.

83. Hsu, C.W.; Chang, C.C.; Lin, C.J. A Practical Guide to Support Vector Classification (Technical Report); Department of Computer Science, National Taiwan University: Taipei, Taiwan, 2003.

84. Bruzzone, L.; Carlin, L. A multilevel context-based system for classification of very high spatial resolution images. IEEE Trans. Geosci. Remote Sens. 2006, 44, 2587-2600.

85. Foody, G.M. Status of land cover classification accuracy assessment. Remote Sens. Environ. 2002, 80, 185-201.

86. Olofsson, P.; Foody, G.M.; Stehman, S.V.; Woodcock, C.E. Making better use of accuracy data in land change studies: Estimating accuracy and area and quantifying uncertainty using stratified estimation. Remote Sens. Environ. 2013, 129, 122-131.

87. Foody, G.M. Thematic map comparison: Evaluating the statistical significance of differences in classification accuracy. Photogramm. Eng. Remote Sens. 2004, 70, 627-633.

88. IUSS Working Group WRB. World Reference Base for Soil Resources 2006; World Soil Resources Reports No. 103; Food and Agriculture Organization (FAO): Rome, Italy, 2006.

89. Food and Agriculture Organization (FAO). Global Agriculture Towards 2050; FAO: Rome, Italy, 2009.

90. Tilman, D.; Balzer, C.; Hill, J.; Befort, B.L. From the cover: Global food demand and the sustainable intensification of agriculture. Proc. Natl. Acad. Sci. USA 2011, 108, 20260-20264.

91. Ray, D.K.; Mueller, N.D.; West, P.C.; Foley, J.A.; Hart, J.P. Yield trends are insufficient to double global crop production by 2050. PLOS ONE 2013, 8, 1-8.

92. Rodriguez-Galiano, V.; Ghimire, B.; Rogan, J.; Chica-Olmo, M.; Rigol-Sanchez, J. An assessment of the effectiveness of a Random Forest classifier for land-cover classification. ISPRS J. Photogramm. Remote Sens. 2012, 67, 93-104.

93. Ricardo, D. On the Principles of Political Economy and Taxation; John Murray: London, UK, 1821. 
94. Von Thünen, J.H. Von Thünen's Isolated State: An English Edition of: (1826) der Isolierte Staat. Edited with an Introduction by Peter Hall; Pergamon Press: Oxford, UK, 1966.

95. Larsson, S.; Nilsson, C. A remote sensing methodology to assess the costs of preparing abandoned farmland for energy crop cultivation in northern Sweden. Biomass Bioenergy 2005, 28, 1-6.

96. Bergen, K.M.; Dronova, I. Observing succession on aspen-dominated landscapes using a remote sensing-ecosystem approach. Landsc. Ecol. 2007, 22, 1395-1410.

97. Stehman, S.V. Model-assisted estimation as a unifying framework for estimating the area of land cover and land-cover change from remote sensing. Remote Sens. Environ. 2009, 113, 2455-2462.

98. McIver, D.; Friedl, M. Using prior probabilities in decision-tree classification of remotely sensed data. Remote Sens. Environ. 2002, 81, 253-261.

(c) 2014 by the authors; licensee MDPI, Basel, Switzerland. This article is an open access article distributed under the terms and conditions of the Creative Commons Attribution license (http://creativecommons.org/licenses/by/3.0/). 